\title{
Identificando as principais dificuldades na compreensão de gráficos pelos cidadãos cegos \\ Alternative Title: Identifying the main difficulties in comprehension of graphics by blind citizens
}

\author{
João Marcelo Santos Marques \\ Departamento de Informática \\ Aplicada, Universidade Federal do \\ Estado do Rio de Janeiro \\ Av. Pasteur 458 - Urca, Rio de \\ Janeiro, Brasil \\ +55212142-4595 \\ joao.marques@uniriotec.br
}

\author{
Simone Bacellar Leal Ferre ira \\ Departamento de Informática \\ Aplicada, Universidade Federal do \\ Estado do Rio de Janeiro \\ Av. Pasteur 458 - Urca, Rio de \\ Jane iro, Brasil \\ $+55212530-8051$ \\ simone@uniriotec.br
}

\author{
Claudia Cappelli \\ Departamento de Informática \\ Aplicada, Universidade Federal do \\ Estado do Rio de Janeiro \\ Av. Pasteur 458 - Urca, Rio de \\ Janeiro, Brasil \\ $+55212530-8051$ \\ claudia.cappelli@uniriotec.br
}

\begin{abstract}
RESUMO
Com o avanço da internet e a era da transparência, diversas organizações começaram a divulgar uma variedade de informações e serviços na web. Porém muitas dessas informações são inacessíveis para os deficientes visuais, como as informações apresentadas em forma gráfica. Buscando reduzir esta falta de acessibilidade a essas informações, a presente pesquisa se propõe a identificar as principais dificuldades relacionadas ao entendimento de imagens em sites web governamentais para cidadãos cegos e para propor recomendações para o desenvolvimento destes, de forma que os profissionais envolvidos na disponibilização de informações gráficas possam torná-las mais inteligíveis aos cidadãos cegos.
\end{abstract}

\section{Palavras-chave}

Acessibilidade, entendimento de informações gráficas, transparência.

\begin{abstract}
With the advancement of the internet and the era of transparency, several organizations disseminate a variety of information and services on the web. But much of this information are inaccessible to the visually impaired, such as information presented in graphic form. Seeking to reduce this lack of accessibility to this information the present research aims to identify the main difficulties related to the understanding of images on government websites for blind citizens and to propose recommendations for the development of these, so that the professionals involved in the information can make them more intelligible to blind citizens.
\end{abstract}

\section{CCS Concepts}

Permission to make digital or hard copies of all or part of this work for personal or classroom use is granted without fee provided that copies are not made or distributed for profit or commercial advantage and that copies bear this notice and the full citation on the first page. To copy otherwise, or republish, to post on servers or to redistribute to lists, requires prior specific permission and/or a fee.

SBSI 2017, June 5th-8th, 2017, Lavras, Minas Gerais, Brazil.

Copyright SBC 2017.

\begin{abstract}
- Human-centered computing - Interaction paradigms - Graphical user interfaces
\end{abstract}

Keywords

Accessibility, information understanbility, transparency.

\section{INTRODUÇÃO}

Com o advento da internet e o surgimento da era da transparência, organizações de diversos segmentos da sociedade começaram a divulgar suas informações na web, possibilitando os usuários de qualquer categoria acessar uma variedade de serviços.

Porém, recursos visuais, como figuras, gráficos e representações diagramáticas diversas, são divulgadas na web, muitas vezes sem o cuidado de proporcionar textos que possam ser processados pelos leitores de tela (programas que fazem a leitura do código HTML de páginas web e repassam aos usuários, através de um sintetizador de voz humana). Não basta que sejam adicionados textos alternativos às figuras; esses textos devem transmitir uma mensagem compreensiva para seus usuários [1].

A ausência de recursos, como os textos alternativos, ainda é uma barreira a ser vencida pelos deficientes visuais totais, que não são poucos, e têm o direito à informação, sendo assegurada por normas jurídicas, diretrizes e recomendações de acessibilidade.

Os dados do último censo de 2010 realizado pelo IBGE (Instituto Brasileiro de Geografia e Estatística), relatam que 6,6 milhões de pessoas declararam que apresentam algum tipo de deficiência visual severa (grande dificuldade de enxergar ou que não conseguem de modo algum). Desses 6,6 milhões, 506,3 mil declararam ser cegos [2].

O presente trabalho tem por objetivo: identificar as principais dificuldades no entendimento de informações gráficas pelos cidadãos deficientes visuais totais de modo a propor recomendações para o projeto das interfaces de sites web para facilitar o entendimento desta forma de apresentação de informações para este público alvo.

\section{FUNDAMENTAÇÃO TEÓRICA}

\subsection{Lei de Acesso à Informação}


Iniciativas em diversos países no mundo possibilitam o acesso às informações públicas ao cidadão, como as Leis de Acesso à Informação. Uma dessas inciativas é a Lei de Acesso à Informação (LAI) - Lei 12.527/2011, promulgada em abril de 2011, que estabelece que os governos de todas as esferas (municipal, estadual e federal) devem fornecer instrumentos próprios para a recepção e o envio de pedidos de informação da sociedade civil, pois toda a informação que está sob a guarda do governo brasileiro é pública [3].

Nessa Lei está prevista a adoção de medidas que possam garantir a acessibilidade ao conteúdo web para pessoas com deficiência que independente de suas condições físicas-motoras.

\subsection{Acessibilidade}

A acessibilidade consiste em oferecer ao indivíduo autonomia, mesmo que as condições físicas ou mentais, culturais ou sociais sejam desfavoráveis, com intuito de proporcionar o acesso a lugares, estudos, serviços, transportes, meios de comunicação, tecnologias em geral e entretenimentos a todos [4] e [5].

A acessibilidade digital é mais específica e refere-se apenas ao acesso físico, de equipamentos e programas adequados, de conteúdo e apresentação da informação em formatos alternativos; a acessibilidade na Internet consiste na fruição dos recursos da rede mundial de computadores e na acessibilidade na $W e b$, ou eacessibilidade, e diz respeito especificamente ao componente da Web [6] e [7].

Das normas jurídicas, destaca-se a Lei Brasileira de Inclusão da Pessoa com Deficiência que retrata a acessibilidade no seu art. 53 "A acessibilidade é direito que garante à pessoa com deficiência ou com mobilidade reduzida viver de forma independente e exercer seus direitos de cidadania e de participação social" [8].

\subsection{Diretrizes de Acessibilidade}

As diretrizes e recomendações de acessibilidade surgiram para orientar desenvolvedores de interfaces web na implementação de funcionalidades que possam tornar essas interfaces acessíveis para qualquer tipo de público de deficientes. Um exemplo são as diretrizes de acessibilidade para conteúdo web, WCAG (web content accessibility guidelines), [9] elaborado pelo consórcio web, W3C, [10] em cooperação com a sociedade civil e diversas organizações. É composta por quatro princípios: perceptível, operável compreensível e robusto, e contempla na sua última versão " 2.0 " um conjunto de doze diretrizes.

No contexto brasileiro o modelo de acessibilidade do governo eletrônico brasileiro (e-mag) [11] é um outro exemplo de recomendação, elaborado com bases em normas internacionais e documentos sobre acessibilidade de diversos países. Esse modelo foi construído para atender as necessidades do governo brasileiro, visando proporcionar a inclusão social de pessoas com deficiência. $\mathrm{Na}$ sua atual versão "3.1” está divido em seções (marcação, comportamento, conteúdo/informação, apresentação/design, multimídia e formulários) abrangendo quarenta e cinco recomendações.

\subsection{Trabalhos Relacionados}

Greenbacker [12] propôs a construção de um sistema com a finalidade de melhorar acesso ao conteúdo de documentos multimodais contendo gráficos de linha, para pessoas com deficiência visual. Esse sistema tinha como objetivo reconhecer e transmitir um resumo coerente das informações de um gráfico durante a leitura por um leitor de tela.
Rodríguez [13] propôs um software que utiliza linguagem controlada para verificar a adequação de textos alternativos para imagens, com base em um conjunto de regras orientadas à acessibilidade condizentes ao idioma francês.

Santos [14] propôs na área da engenharia de software, o desenvolvimento de um editor de diagramas que utiliza notações da linguagem UML (Unified Modeling Language) possibilitando que os cegos possam construir e documentar artefatos de sistemas de software.

Nos trabalhos estudados na literatura, percebe-se a ausência de características de transparência de informação que possam melhorar a apresentação e entendimento de informações gráficas.

\section{MÉTODO DE PESQUISA}

A presente pesquisa foi composta das seguintes etapas: A) Estudo das características do catálogo de transparência; B) Identificação das características do E-MAG relacionadas ao entendimento de imagens por cidadãos cegos; C) Realização de um estudo de caso; D) Elaboração das recomendações.

A) Estudo das características do catálogo de transparência Foi realizado um estudo das características do Catálogo de Transparência [15] formado por um SIG (Softgoal Interdependency Graph) que pode ser definido como um "grafo de interpendencia que desempenha um papel central na visualização analisando requisitos não funcionais - NFRs" [16] que possibilita a "identificação das relações de dependências entre seus elementos e suas contribuições" [15], através de operacionalizações e mecanismos de implementação. No SIG foram identificadas características com base no levantamento bibliográfico que podem ser utilizadas para aprimorar o entendimento de informações gráficas para os deficientes visuais totais.

B) Identificação das características no E-MAG relacionadas ao entendimento de imagens por cidadãos cegos

Com base nas seções definidas para a implementação das recomendações do Modelo de Acessibilidade do Governo Eletrônico [11], algumas características foram relacionadas à compreensão de imagens para os cegos.

Da seção sobre conteúdo/informação, destacam-se três recomendações. A recomendação 3.6, determina que deve ser fornecida uma alternativa textual, isto é, uma descrição para as imagens da página, utilizando-se, para tanto o atributo alt. Descrever uma imagem é subjetivo e a descrição deve ser adaptada ao contexto da imagem logo, destaca-se a característica adaptabilidade que é necessária, para que as interfaces de sites possam ser navegáveis e compreendidas por diversos públicos, como os cegos.

Da recomendação 3.11 (Garantir a leitura e compreensão das informações), destaca-se a clareza, que determina que todo texto deve ser compreendido por usuários com baixo letramento.

A característica explicação presente na recomendação 3.12 (Disponibilizar uma explicação para siglas, abreviaturas e palavras incomuns) determina que se deve disponibilizar na primeira ocorrência de siglas, abreviaturas ou palavras incomuns (ambiguas, desconhecidas ou utilizadas de forma muito especifica sua explicação ou forma completa, expressa no próprio texto, ou em um glossário ou, então, através da utilização do elemento abbr. Essa característica aparece como importante contribuição tendo em vista que os usuários necessitam de explicações sobre os elementos dispostos em interfaces web. Os elementos que compõem um gráfico, como (títulos, legendas, valores e outros). 
A intuitividade é uma característica relevante para a compreensão dos cegos, que utilizam as funcionalidades já presentes nas interfaces e que são familiares. Essa característica, descrita na recomendação 1.7 (Separar links adjacentes), define que Links adjacentes devem ser separados por mais do que simples espaços, para que não fiquem confusos, em especial para usuários que utilizam leitor de tela. Para isso, é recomendado o uso de listas, onde cada elemento dentro da lista é um link. As listas podem ser estilizadas visualmente com CSS para que os itens sejam mostrados da maneira desejada, como um ao lado do outro.

A característica completeza é necessária, pois possibilita que os usuários acessem as funcionalidades já disponíveis no site, como um formulário para opinarem a respeito da acessibilidade do gráfico. Essa característica está implícita na recomendação 6.2 (Associar etiquetas aos seus campos) que retrata, as etiquetas de texto (elemento LABEL) devem estar associadas aos campos correspondentes no formulário, através dos seus atributos, os quais deverão ter o mesmo valor.

C) Realização de um estudo de caso

O estudo de caso foi realizado através das seguintes etapas:

\section{a. Seleção do perfil dos usuários participantes}

Foram selecionados seis deficientes visuais totais que formaram um grupo de uma das unidades de análise. A convocação dos voluntários foi feita, a partir de convite por correio eletrônico ou por telefone ou pessoalmente.

O perfil de cada participante atendeu aos seguintes requisitos: possuir pelo menos escolaridade de nível médio completo; ter experiência na navegação em sites há mais de dois anos e conhecer de algum gráfico estatístico do tipo barra, linha ou pizza.

Para manter o sigilo e o anonimato das informações, os participantes voluntários foram codificados pela letra inicial V.

\section{b. Seleção dos sites e gráficos para avaliação}

Foram analisados vários sites governamentais que apresentaram imagens de gráficos estatísticos para a realização das tarefas pelos participantes. Escolheu- se três sites:

Site da Prefeitura Municipal de Itupeva do Estado de São Paulo (http://itupeva.sp.gov.br/), onde podem ser visualizadas informações na forma de gráfico sobre a evolução da população do município no período de 2000 a 2011.

Site da Reestruturação e Expansão das Universidades Federais (http://reuni.mec.gov.br/) do Ministério da Educação, onde foi possível encontrar informações a respeito da expansão da rede federal de educação superior criadas no período de 2003-2010.

E o site do Tribunal Regional do Trabalho da $1^{\text {a }}$ Região (http://trt1.jus.br/), onde foi possível visualizar o quantitativo dos servidores do tribunal que possuem algum tipo de deficiência/mobilidade reduzida e da opinião dos servidores, a respeito das condições do ambiente de trabalho se estão adequadas as suas necessidades no ano 2013.

Para a seleção desses sites foi levado em consideração pelo menos um dos seguintes aspectos:

1. Possibilitar aos cidadãos o acesso às informações públicas de acordo com os dispositivos da Lei 12.527/2011 - Lei de Acesso à Informação [3];

2. Ter sido avaliado por alguma ferramenta automática de avaliação de acessibilidade e apresentar no site o "selo de acessibilidade" em conformidade com os níveis AAA.

\section{c. Definição do método de avaliação}

O método de avaliação escolhido foi a observação de usuários em ambiente controlado na forma de laboratório móvel, onde foi avaliada a interação desses participantes em tarefas executadas em interfaces dos sites contendo imagens gráficas. Esse método foi escolhido para permitir um maior controle sobre o ambiente de teste evitando a ocorrência de alguns fatores externos, como conversas no ambiente de testes envolvendo o participante e pessoas que não estejam participando dos testes, ruídos, barulhos que desviassem a atenção do participante durante a execução das tarefas podendo alterar o resultado dos testes.

\section{d. Definição das tarefas}

Foram definidas tarefas que pudessem ser executadas pelos voluntários cegos, visando a identificação e o entendimento de informações dispostas em gráficos (barras simples na vertical, pizza e linhas).

As tarefas definidas para o gráfico do tipo barras foram: 1) descrever o título do gráfico; 2) informar o título do eixo horizontal; 3 ) informar o título do eixo vertical; 4) informar a quantidade de barras; 5) informar o maior valor entre as barras; 6) informar o menor valor entre as barras; 7) informar o intervalo de valores no eixo horizontal; 8) informar o intervalo de valores no eixo vertical; 9) informar a fonte de publicação.

Para o gráfico do tipo linhas foram: 1) descrever o título do gráfico; 2) informar o título do eixo horizontal; 3 ) informar o título do eixo vertical; 4) informar o intervalo de valores no eixo horizontal; 5) informar o intervalo de valores no eixo vertical; 6) informar a quantidade de linhas; 7) informar o maior valor da linha; 8) informar o menor valor da linha; 9) informar a fonte de publicação.

Para o gráfico de pizza foram propostas as seguintes tarefas: 1) descrever o título do gráfico; 2) descrever as informações da legenda; 3) informar o valor de cada setor da pizza; 4) informar o maior valor entre os setores da pizza; 5) informar o menor valor entre os setores da pizza; 6) informar a quantidade de setores do gráfico; 7) informar a fonte de publicação.

\section{e. Execução dos testes}

Antes da execução dos testes foi apresentado o "Termo de Consentimento" com detalhes sobre o objetivo da pesquisa. As dúvidas relacionadas aos questionários e procedimentos sobre os testes foram sanadas.

Dois leitores de tela foram escolhidos: o NVDA (NonVisual Desktop Access) e o DOSVOX. O NVDA foi escolhido por ser um software de acesso gratuito, sendo executado na plataforma Windows em mais de quarenta e três idiomas [17], além de ser familiar para os participantes. Já o DOSVOX [18], por ser uma também, gratuito e utilizada pelos participantes em um dos locais de testes que foi o instituto "União dos Cegos do Brasil".

Foram elaborados dois questionários (um pré-teste e outro pósteste) para a realização de entrevistas com os participantes. O primeiro visou identificar o perfil de cada voluntário e o segundo foram abordadas questões sobre o entendimento e apresentação das informações gráficas.

Observação: os testes foram realizados no período de 28/10/2016 a 23/11/2016. Durante esse período, o site da Prefeitura Municipal de Itupeva tinha o selo de acessibilidade, mas no momento não tem mais.

\section{f. Análise dos Resultados}

Os dados coletados dos questionários, na observação dos participantes voluntários durante a execução das tarefas, nos 
registros das impressões, reações, dificuldades encontradas no entendimento e na apresentação dos dados gráficos, serviram de insumos para a elaboração das recomendações para a implementação de gráficos nas interfaces de sites web governamentais para os cegos.

D) Elaboração das recomendações

A partir da análise dos resultados dos testes, da identificação das características de transparência [15] e das características do [11] para a compreensão de imagens por cegos, foram elaboradas as recomendações.

\section{OBSERVAÇÕES COM USUÁRIOS}

\subsection{Organização do Ambiente de Testes}

Para realização dos testes foi utilizado o seguinte material: 1) Notebook com processador (core i3 - 4GHZ - 1 Tera HD), utilizando Sistema Operacional Windows 10; 2) Software de captura de tela "Icecream Screen Recorder versão 4.50"; 3) Gravador de voz de bolso; 4) Câmera de vídeo integrada ao notebook com dois microfones para registar as reações, impressões do usuário; 5) Um modem 4G com conexão $W i-f i$; 6) Termo de consentimento e descrição das tarefas que poderiam ser lidas pelo usuário utilizando o leitor de tela ou solicitando ao pesquisador; 7) Questionários pré e pós-testes; 8) Leitor de tela DOSVOX e NVDA, a critério do usuário.

O software para captura de tela "Icecream Screen Recorder versão 4.50 " foi escolhido por permitir a visualização de recursos, como histórico das gravações, tempo de duração de cada gravação e o tamanho do arquivo gerado de cada gravação e por ter acesso gratuito durante um período de trinta dias.

As páginas que continham informações sobre o termo de consentimento e as tarefas para serem executadas pelos usuários foram elaboradas em conformidade com as recomendações do EMAG [9] e com padrões web, como (HTML5 e WAI-ARIA).

Participaram dos testes dois cegos, contactados diretamente pelo pesquisador durante o evento "Todos@Web" [10]. Três usuários foram recrutados, através do "Instituto União dos Cegos do Brasil" e um voluntário do Ministério Público Federal (Procuradoria da República do Rio de janeiro), totalizando seis participantes.

\subsection{Teste Piloto}

A usuária V1 optou por realizar o teste em sua residência. O tempo total de duração dos testes foi de 48 minutos e 15 segundos incluindo a configuração do ambiente. Para tornar o ambiente familiar para a usuária foi proposto que ela usasse o seu próprio teclado, mas ela preferiu o teclado do notebook do pesquisador.

A participante optou pelo leitor NVDA por já estar familiarizada com o sintetizador "Microsoft Speech API version 5" e com a voz "ScanSoft Raquel_Full_22Khz". O navegador selecionado por V1 foi o "Google Chrome", mesmo tendo sido apresentados outros navegadores, como (Firefox e Microsoft Internet Explorer).

Foi apresentado para V1, no site do município de Itupeva do Estado de São Paulo, um gráfico de barras sobre a evolução da população deste município (Figura 1).

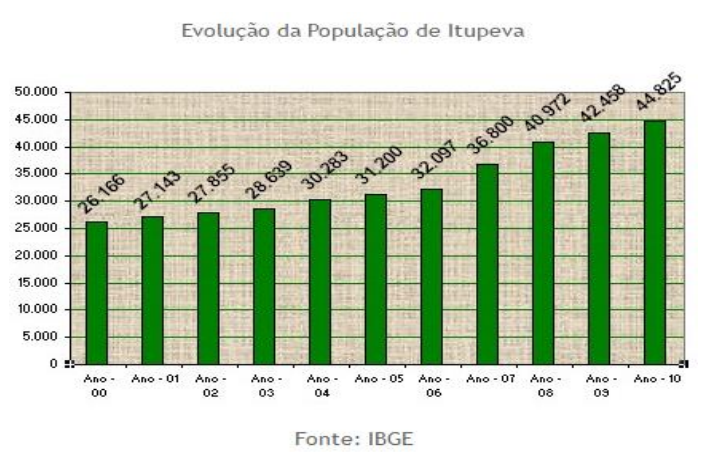

Figura 1. Evolução da população de Itupeva de 2000 a 2010.

Para executar o teste, o pesquisador fez a leitura de cada tarefa para a voluntária. Ao navegar na página do site utilizando teclas de atalho do leitor, percebeu-se que a voluntária não teve muitas dificuldades em localizar o gráfico.

\section{Gráfico de Barras}

A voluntária realizou a tarefa 1 (título do gráfico), sem dificuldades e conseguiu informar o título do gráfico. Nas tarefas (2 a 8) a voluntária não teve sucesso em identificar os elementos do gráfico. A tarefa 9 que foi a (fonte da publicação do gráfico) a usuária conseguiu identificar.

Ao final do teste constatou-se que a usuária só conseguiu identificar duas informações: o título e a fonte de publicação.

\section{Gráfico de Linhas}

Foi apresentado para V1 uma página web contendo um texto acima da imagem gráfica a V1 (Figura 2). O texto descrito na página não tinha nenhuma relação com as informações gráficas. No elemento $<$ alt $>$ associado a imagem gráfica estava descrito "gráfico expansão".

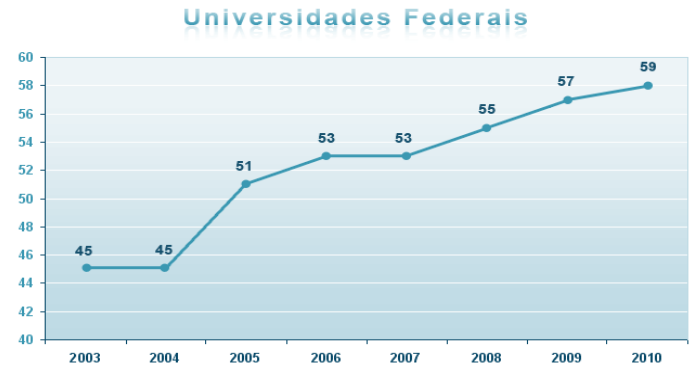

Figura 2. Expansão da rede federal de educação superior.

Encontrou muita dificuldade em localizar o gráfico na página e percorreu toda a página em busca de informações sobre o gráfico, fazendo algumas indagações ao pesquisador: "Aonde está o gráfico?”; "Aonde estão as informações?”; "Tem um gráfico na página?"; "Essa página não tem nenhum tipo de acessibilidade!"; "O que é gráfico expansão?"; "Estou tentando qualquer coisa para obter alguma informação, inclusive utilizando a tecla tab, porém não vai!".

Diante dos comentários de V1, o pesquisador ratificou que havia na página um gráfico, cuja a descrição relacionada ao gráfico era "gráfico expansão".

A única informação que V1 conseguiu obter do gráfico foi "gráfico expansão" e para a usuária não tinha nenhum significado e ela continuou não tendo entendimento sobre o gráfico.

Terminada as tarefas, o pesquisador relatou para V1 que a página tinha o "selo de acessibilidade Brasil". V1 respondeu: "se tem o 
selo de acessibilidade é brincadeira, é maquiagem o que fazem com a gente que é deficiente não colocando nenhuma informação para explicar o gráfico".

\section{Gráfico de Pizza}

O gráfico de pizza disposto em um frame (Figura 3) foi apresentado para a usuária V1. O gráfico era muito pequeno e podia ser ampliado, a partir de um clique no próprio gráfico ou em um dos links, abaixo dele. Os links tinham as seguintes descrições: "Gráfico SGP.jpg" e "Baixar 18,9K".

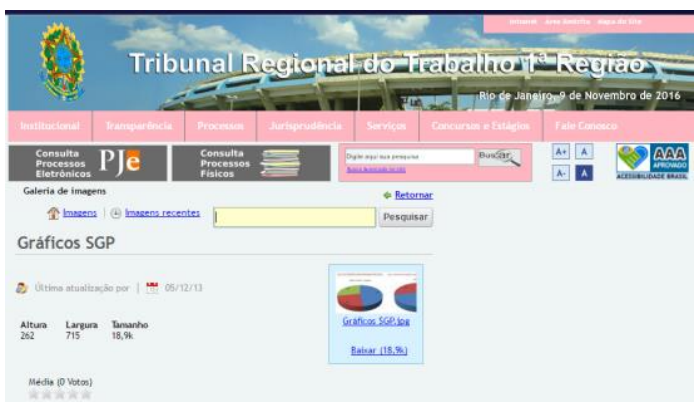

Figura 3. Tipo de deficiência/mobilidade reduzida; e sobre o ambiente de trabalho.

O pesquisador solicitou a V1 que clicasse no link "Gráfico SGP.jpg", onde foi aberta uma janela contendo duas imagens (Figura 4). A primeira tinha informações sobre o tipo de deficiência/mobilidade reduzida com três legendas (uma na cor azul referindo-se à deficiência física; a outra na cor vermelha sobre deficiência visual e outra na cor verde que se referia a deficiência auditiva).

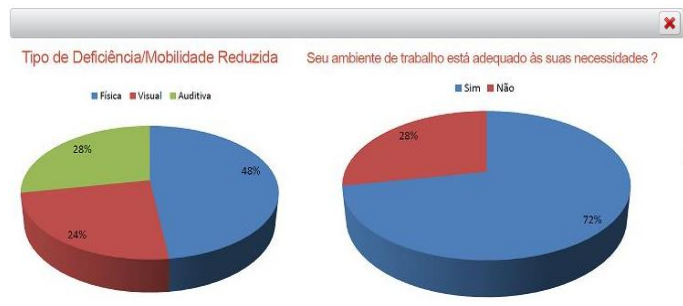

Figura 4. Gráficos ampliados.

$\mathrm{Na}$ segunda imagem foram exibidas informações sobre uma pesquisa indagando se o ambiente de trabalho se estava adequado às necessidades dos servidores do Tribunal Regional do Trabalho $1^{\text {a }}$ Região. Nessa imagem apareciam dois setores: um com $28 \%$ que correspondia aos servidores que responderam "sim" e o outro com $72 \%$ dos servidores que responderam "não".

A única informação que a usuária conseguiu obter foi: "imagem ilustrativa" e comentou: "O que é isso, imagem ilustrativa? Imagem sem informação!"; "Ninguém merece ter acesso a nenhuma informação!"; "Para mim não tem nada para me informar!"; "Não há descrição nem nos links!"; "O que é altura, largura e tamanho?"; "Aonde está o gráfico de pizza?" !”.

Após a realização dos testes, o pesquisador descreveu as informações que estavam presentes nos gráficos (barras, linhas e pizza) que eram inacessíveis aos usuários e reiterou que todas as páginas possuíam o "selo de acessibilidade Brasil".

\section{Entrevista pós-testes}

$\mathrm{Na}$ entrevista pós-testes buscou-se abordar questões sobre a identificação de alguns elementos do gráfico, como (títulos nos eixos horizontal e vertical; legendas no gráfico de pizza; o valor de algum ponto do gráfico de linhas; o número de barras, linhas e setores; os maiores e menores valores nos três tipos de gráficos e outros elementos). Entretanto não foi possível obter muitas informações, pois a voluntária teve muita dificuldade de entender, identificar e localizar os gráficos nas páginas web tendo a mesma resposta para todas as questões que foi: "tive dificuldade total".

Mediante essas respostas, foi necessário fazer ajustes no questionário elaborando novas questões que fossem mais diretas para a identificação dos elementos em um gráfico, como (quais informações gráficas que você teve dificuldade de identificar em um gráfico de barras?; quais informações gráficas você teve dificuldade de identificar em um gráfico de linhas?; quais informações gráficas você teve dificuldade de identificar em um gráfico de pizza?; você acha que as informações descritas em um gráfico deveriam ser mais claras explicando por exemplo o uso de termos técnicos, abreviaturas?).

Foi pedido também à usuária para responder a algumas questões relacionadas às características de transparência, como qual tipo de detalhamento de descrição das imagens, necessidade de uso de teclas de atalhos para melhor explicar os valores de um gráfico, necessidade de disponibilizar formulário para sugestões e opiniões sobre as informações em um gráfico, necessidade de rastreamento de dados para maiores informações.

Foram obtidas, respectivamente as seguintes respostas: 1. Todas as informações devem ser disponibilizadas de duas formas: gerais ou detalhadas de acordo com meu interesse e necessidade busco o que procuro; 2. Teclas de atalho podem se chocar com outras teclas que já foram programas de três maneiras diferentes: pelos navegadores, por leitores de tela e pelos desenvolvedores do próprio site. Ser criado um quarto conjunto de teclas de atalho será muito mais teclas para o cego, se acostumar e ficará muito cansativo de se trabalhar; 3. O site acessivel tem que ter uma página dizendo, quais informações de acessibilidade foram implementadas no site. Um canal específico de retorno do usuário para informar, aonde ele está com dificuldade reportando ao desenvolvedor de como tornar o site mais acessivel seria interessante de se ter; 4. Todos os dados, como a fonte, a data, a hora devem ser informados, para que não seja divulgada nenhuma informação errada, sem saber qual foi a fonte, a data/hora. A informação tem que ser fidedigna, para que os usuários não divulguem informações sem saber de onde vieram.

Essa usuária tinha muita experiência com softwares leitores de tela, na navegação em sites web e conhecedora de código HTML, pois já havia trabalhado na área de informática, como Analista de Sistemas e promove palestras, consultorias em acessibilidade.

Nos testes observou-se que o leitor de tela "NVDA" identificou $a$ data e a hora de criação do gráfico de barras e a data e hora de atualização do gráfico de pizza. Essas informações foram consideradas como novas tarefas.

\subsection{Testes com demais Usuários}

$\mathrm{O}$ primeiro usuário escolheu realizar o teste na residência do pesquisador. Os testes com usuários V2, V3, V4 e V5 foram realizados no "Instituto União de Cegos do Brasil" e com o V6 em seu ambiente de trabalho. Cada participante foi conduzido um de cada vez para a sala de testes, a pedido do pesquisador, para que não houvesse interferência nos resultados e comentários entre si. Foram apresentados os leitores de tela (DOSVOX e NVDA).

Usuário V2 - O tempo total de duração dos testes foi de 33 minutos e 4 segundos, incluindo a preparação para os testes. V2 optou pelo 
NVDA, o sintetizador "eSpeak $N G$ ", a voz "Max" e o navegador "Firefox" por serem familiar.

\section{Gráfico de Barras}

As informações sobre as tarefas (o título, a data e a hora da criação do gráfico e a fonte de publicação do gráfico) foram descritas sem dificuldades por ele. As demais tarefas não foram identificadas, devido à falta de descrição nos elementos, atributos da linguagem HTML para leitura do NVDA.

As informações comentadas pelo usuário durante a realização das tarefas foram: "Consigo identificar a informação: criado em Quinta, 13 janeiro 2011 17:19”; “Tem um título dizendo Evolução da População de Itupeva"; "Uma fonte IBGE"; "Cara, não consigo ouvir mais nada do leitor de tela sobre o gráfico”.

\section{Gráfico de Linhas}

O usuário não conseguiu executar as tarefas estabelecidas, porque não obteve descrição do leitor de tela, somente, a informação "gráfico expansão" e comentou: "É o seguinte: tem um texto grande"; "O NVDA está me dizendo: conheça o mapa de expansão das universidades. Isso tem alguma coisa haver com o gráfico?"; "Na verdade, o NVDA parou de falar"; "Nenhuma informação é falada mais!"; "Só ouvi: gráfico expansão".

\section{Gráfico de Pizza}

Apenas, a tarefa para determinar a data da última atualização do gráfico, foi decodificada pelo leitor de tela. Para as demais tarefas que não consegui realizar, relatou: "o mais perto para mim que pode ser um gráfico é a informação: gráfico SGP"; e "o leitor ficou mudo!", se referindo que não pode obter mais nenhuma informação do NVDA.

\section{Entrevista pós-testes}

$\mathrm{Na}$ entrevista realizada após as observações foi possível entender melhor a experiência com o usuário com relação as caraterísticas de transparência. Por exemplo: o usuário prefere escolher qual o modo de detalhamento para descrever os gráficos, o uso de teclas de atalho para obter informações sobre os títulos dos eixos horizontal e vertical, para procurar o maior e menor valor, o uso de um formulário para sugestões e a importância de ser ter informações sobre a origem dos dados.

Usuário V3 - O usuário levou o tempo de 34 minutos e 31 segundos para realizar os testes. Escolheu o leitor NVDA, o sintetizador de voz "Microsoft Speech API version 5", a voz "ScanSoft Raquel_Full_22Khz", o browse "Google Chrome" e o teclado do notebook do pesquisador utilizando as setas.

\section{Gráfico de Barras}

A descrição do título, a identificação da data e hora da criação do gráfico e a fonte de publicação foram as tarefas que conseguiu realizar, sem maiores dificuldades. As outras tarefas não foram concluídas, porque não houve descrições que pudessem ser lidas pelo NVDA.

Durante os testes relatou: "O NVDA só informa: título, data, hora e fonte. E não tenho acesso a mais nada"; "O leitor não dá referência numérica alguma"; "Fala em evolução da população de Itupeva, mais quantos?".

\section{Gráfico de Linhas}

O usuário não conseguiu realizar nenhuma tarefa, porque não teve acesso às informações, através do NVDA e explanou durante as tarefas: "Mais gráfico em si, não tenho acesso a nada".

\section{Gráfico de Pizza}

A tarefa relacionada (a data da última atualização do gráfico) foi a única tarefa que conseguiu realizar, pois as demais não foram detectadas pelo leitor de tela e ainda disse: "não está falando nada"; "Tá difícil cara", "Gráfico SGP. O que é isso?".

\section{Entrevista pós-testes}

Durante a entrevista foram coletas informações do voluntário que estavam relacionadas as características de transparência, onde observou-se que deveriam ter sido implementadas opções para detalhar o gráfico na forma resumida e completa, a implementação de teclas de atalho, a disponibilização de um formulário para descrever opiniões sobre a acessibilidade do gráfico e informações sobre a atualização dos dados.

Usuário V4 - O voluntário efetuou os testes no tempo de 30 minutos e 34 segundos. Ele, preferiu utilizar o leitor de tela NVDA, a voz "ScanSoft Raquel_Full_22Khz", o sintetizador "Microsoft Speech API version 5" e o "Google Chrome".

\section{Gráfico de Barras}

As tarefas referentes ao título, a data e a hora de criação do gráfico, e a fonte de publicação foram identificadas pelo voluntário. Em relação as demais tarefas o leitor de tela não descreveu nenhuma informação e V4, comentou: "Ele (leitor de tela) fala da população de Itupeva, porém não descreve o gráfico"; "Não consigo ter informações"; "o leitor não descrever dados sobre o gráfico. Não entra nesse detalhe".

\section{Gráfico de Linhas}

O usuário não conseguiu descrever nenhuma informação, porque não havia elementos do HTML identificados pelo NVDA e disse: "Deve estar sendo mostrado nessa página um gráfico com as estatísticas, não é?"; "Não dá para ler"; "Não dá para ouvir do leitor de tela pelo menos alguma coisa que seja acessivel, para que a gente possa visualizar mentalmente"; "O leitor não me dá nenhuma informação de quantidade, de linhas, de fonte, de valores, nada!”; "O que ouço é: gráfico expansão”.

\section{Gráfico de Pizza}

O usuário teve muita dificuldade de localizar e obter alguma informação do gráfico e só foi capaz de concluir a tarefa (a data de atualização do gráfico), porque o leitor conseguir obter descrição e ressaltou: "gráfico SGP! O que é isso?"; "as informações sobre os elementos do gráfico, o que tinha no gráfico, ele (leitor de tela) não disse em nenhum momento!"; "Ficou muito a desejar!"; "O que eles colocaram na página, não corresponde com a realidade (se referindo ao selo de acessibilidade)!”.

\section{Entrevista pós-testes}

No decorrer da entrevista foram abordadas questões sobre características de transparência, onde o usuário informou que prefere obter informações do gráfico que sejam mais detalhadas, a não obrigatoriedade de que sejam programadas teclas de atalho, porque exigiria que os cegos fizessem um curso, para a leitura da página, o uso de um formulário para opinar sobre o gráfico, e informações sobre a proveniência dos dados, como a data, a fonte de publicação dos dados.

Usuário V5 - A usuária realizou os testes no tempo de 24 minutos e 29 segundos. Utilizou o leitor NVDA, a voz "ScanSoft Raquel_Full_22Khz", o sintetizador "Microsoft Speech API version 5", o browser "Google Chrome" e o teclado do notebook do pesquisador.

\section{Gráfico de Barras}

As tarefas (informar título do gráfico, data e hora da criação do gráfico e a fonte de publicação do gráfico) foram informadas pela 
voluntária. As outras tarefas não foram detectadas pelo leitor de tela.

\section{Gráfico de Linhas}

A participante não concluiu nenhuma tarefa, pois o NVDA não conseguiu extrair informações do gráfico e ela, comentou: "Só ouço a informação: gráfico expansão"; "Não consigo obter mais informação"; "Esse gráfico não dá descrição".

\section{Gráfico de Pizza}

No gráfico de pizza a usuária, somente, informou a data de atualização do gráfico que foi: "Última atualização 05/02/2013". Para as outras tarefas não conseguiu ouvir nenhuma descrição do leitor de tela.

\section{Entrevista pós-testes}

Das respostas da usuária registradas durante a entrevista, algumas estavam associadas às características de transparência: ela prefere ter informações que sejam mais detalhadas para a identificação do conteúdo que esteja no gráfico; vê a necessidade que sejam implementadas teclas de atalho e a elaboração de um formulário para sugestões, e sobre a rastreabilidade dos dados de onde estão vindas as informações, como por exemplo a fonte de publicação e outras informações e acha que é muito importante de ser ter em um gráfico.

Usuário V6 - O usuário levou 27 minutos e 50 segundos para realizar os testes. Ele, preferiu utilizar o leitor de tela NVDA, o sintetizador de voz "Microsoft Speech API version 5", a voz "ScanSoft Raquel_Full_22Khz" e o browse "Microsoft Internet Explorer".

\section{Gráfico de Barras}

As tarefas, como (a descrição do título, a fonte de publicação, a identificação da data e hora da criação do gráfico) foram cumpridas pelo usuário. Os elementos do gráfico relacionados a outras tarefas, não foram identificados pelo NVDA e V6, disse: "Não dá informação"; "Não, não, não ouço informação"; "A descrição do gráfico aqui não tem”; "Esse detalhamento todo do gráfico sobre as informações não consigo ter "; e "Ouço população atual e o que significa?".

\section{Gráfico de Linhas}

O voluntário não conseguiu concluir as nove tarefas propostas para o gráfico, porque não obteve informação do NVDA. Navegando na página ouviu do leitor: "gráfico expansão". Diante dessa informação, disse: "Deve ser a respeito do gráfico"; "Agora a descrição sobre isso, não tem não!”.

\section{Gráfico de Pizza}

Observou-se que, apenas, a tarefa (a data da última atualização do gráfico - 05/02/2013) foi concluída pelo usuário. As demais tarefas, o NVDA não conseguiu identificar e o usuário explanou: "Na verdade, ele (NVDA) não está lendo nada"; "Esse gráfico era para ele (leitor de tela) ter informado alguma coisa!" ; "Mais não leu nada!".

\section{Entrevista pós-testes}

Depois dos testes, foram anotadas algumas com foco em características de transparência, onde se percebeu que o usuário opta pelas informações mais completas (detalhadas), acha complicado de se ter teclas de atalho, pois se tivesse apenas o detalhamento do gráfico seria suficiente, é desnecessário um formulário no site, caso não haja descrições sobre os elementos do gráfico, e sobre a divulgação de informações sobre a origem dos dados não acha necessário.
Participante não considerado - O participante que não foi considerado levou 17 minutos e 58 segundos, quando tentava realizar as tarefas no gráfico de barras, optando para os testes, o DOSVOX, o sintetizador "ScanSoft Raquel_Full_22Khz", o "Google Chrome" e o teclado do notebook do pesquisador.

Durante a realização dos testes e nos relatos dos voluntários se pode perceber características como (detalhamento e rastreabilidade).

A característica detalhamento é importante, porque muitos cegos não têm acesso às informações detalhadas, como quantidade de barras, intervalos entre os valores, maior e menor valor e outros elementos do gráfico.

Já a característica rastreabilidade possibilita que os cegos possam ter conhecimento da proveniência da informação, como data, a hora da criação do gráfico, responsáveis pela divulgação e outras informações sobre a origem dos dados.

\section{RECOMENDAÇÕES}

Com base nas características de transparência identificadas na literatura e, principalmente, no estudo de caso com os cegos, para um melhor entendimento de informações gráficas para cidadãos cegos, a fim de orientar os envolvidos no processo de disponibilização de informações gráficas para torná-las acessíveis em interfaces web, propõe-se as seguintes recomendações: 1 . Disponibilizar informações utilizando textos alternativos; 2. Descrever títulos, legendas, maior e menor valores e seus intervalos, a quantidade de barras ou linhas ou setores em uma linguagem de mais fácil compreensão; 3. Disponibilizar uma página contendo um formulário, para que os cegos possam dar sugestões, opiniões sobre o gráfico; 4. Exibir um glossário para descrever as siglas, as abreviaturas, os símbolos, os termos técnicos utilizados na imagem do gráfico; 5. Apresentar a data, a hora que foram atualizados, criados, modificados ou extraídos os dados, a entidade, órgão, responsável pela divulgação, a fonte ou notas sobre a publicação.

\section{CONCLUSÕES}

Os problemas vistos na literatura retratam a necessidade de se ter uma maior preocupação na disponibilização de informações gráficas em sites, visando torná-los acessíveis, possibilitando o entendimento dessas informações às pessoas que apresentam algum tipo de deficiência, como os deficientes visuais totais.

A ausência de acessibilidade e a consequente dificuldade de entendimento das informações gráficas pode ser percebida, através do levantamento bibliográfico, e principalmente, durante a execução das tarefas e nas entrevistas com os voluntários.

Para execução das tarefas foram escolhidos três sites governamentais com "selo de acessibilidade" em conformidade com os níveis AAA que apresentaram imagens de gráficos estatísticos para a realização de testes.

Com base na observação com usuários durante os testes, na literatura abordada, foram identificadas características de transparência que serviram de insumos para elaboração das recomendações para orientar os envolvidos no processo de disponibilização de informações gráficas em torná-las acessíveis em interfaces web.

Como trabalhos futuros poderiam ser construídos monitores táteis que disponibilizassem informações gráficas com base em características de transparência recomendadas, evitando que a responsabilidade fosse onerosa, somente, do produtor da informação. Dessa forma os responsáveis pela disseminação de 
informações gráficas atuariam em conjunto os desenvolvedores de monitores táteis. Esse tipo de contrato entre fornecedor, governo e cidadãos cegos poderia fomentar a elaboração de uma política de acessibilidade compartilhada.

Espera-se que as recomendações propostas possam ser incorporadas na linha de produção das organizações.

A pesquisa limitou-se em realizar os testes com os leitores de tela (DOSVOX e NVDA) por serem gratuitos. Caso os testes tivessem sido executados com outros leitores, os resultados poderiam sofrer alterações.

\section{AGRADECIMENTOS}

Aos coordenadores do "Instituto União dos Cegos" (http://www.uniaodoscegosnobrasil.org.br) por terem cedido o espaço para a realização dos testes; e aos demais voluntários que puderam contribuir para a realização da pesquisa.

\section{REFERÊNCIAS}

[1] Geraldo, J., R., Fortes, R., P., M., 2013. Dificuldades de Usuários cegos na interação com a web: uma análise sobre as pesquisas. Revista de Sistemas e Computação, Salvador, v. 3, n. 2, p. 146-160, jul/dez. 2013.

[2] IBGE, 2016. Instituto Brasileiro de Geografia e Estatística. Disponível em:

http://ibge.gov.br/home/estatistica/populacao/censo2010/cara cteristicas_religiao_deficiencia/default_caracteristicas_religi ao deficiencia.shtm, verificado em agosto/ 2016.

[3] Brasil, 2011. Lei $\mathrm{n}^{\mathrm{o}} 12.527$ de 18 de novembro de 2011. Regula o acesso a informações previsto no inciso XXXIII do art. 5o, no inciso II do § 3o do art. 37 e no $\S 20$ do art. 216 da Constituição Federal; altera a Lei no 8.112, de 11 de dezembro de 1990; revoga a Lei no 11.111 , de 5 de maio de 2005, e dispositivos da Lei no 8.159, de 8 de janeiro de 1991; e dá outras providências. Presidência da República, 2004, p.1. Disponível http://www.planalto.gov.br/ccivil_03/_ato20112014/2011/lei/112527.htm, verificado em julho/2016.

[4] Ferreira, S., B., L, Santos, R., Silveira, D., S., 2007. Panorama da Acessibilidade na web Brasileira, Revista de Controle e Administração v.3, n.2, p.206-235, 2007.

[5] Ferreira, S., B., L., Rodrigues, R., N., 2008. e-Usabilidade Editora LTC, 2008.

[6] Sales, M. B.; Cybis, 2003. W. A. Development of a checklist for the evaluation of the web accessibility for the aged users In: Latin American Conference on Human-Computer Interaction (ACM International conference proceeding Series), 2003, Rio de Janeiro. Proceedings... Nova York: ACM, 2003. v. 46. p. 125-33.

[7] Acessibilidade Brasil, 2008. Recursos de acessibilidade. Disponível em: http://www.acessobrasil.org.br/, verificado em fevereiro/2017.

[8] Brasil, 2015. LEI n ${ }^{\circ} 13.146$ de 6 de julho de 2015. Institui a Lei de Inclusão da Pessoa com Deficiência (Estatuto da Pessoa com Deficiência. Disponível em http://www.planalto.gov.br/ccivil_03/_Ato20152018/2015/Lei/L13146.htm, verificado em novembro/2016.

[9] WCAG, Web Content Accessibility Guidelines 2.0, 2008. Disponível em: https://www.w3.org/TR/WCAG20/, verificado em dezembro/2016.
[10] W3C, 2016. World Wide Web Consortium Escritório Brasil Web. Disponível em: http://www.w3c.br/Home/WebHome, verificado em agosto/2016.

[11] E-MAG. 2014, Modelo de Acessibilidade em Governo

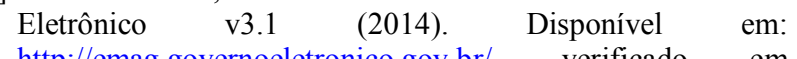
http://emag.governoeletronico.gov.br/, verificado em agosto/2016.

[12] Greenbacker, C., F., Wu, P., Carberry, S., McCoy, K., F., Elzer, S., McDonald, D., D., Chester, D., Demir, S., 2011. Improving the accessibility of line graphs in multimodal documents 2011 SLPAT '11: Proceedings of the Second Workshop on Speech and Language Processing for Assistive Technologies.

[13] Rodríguez, S. V., Lehmann, S., 2015, Acrolinx: a controlledlanguage checker turned into an accessibility evaluation tool for image text alternatives 2015 W4A '15: Proceedings of the 12th $\mathrm{Web}$ for All Conference.

[14] Santos, L., G., Bandeira, A., L., M., Pansanato, L., T., E., Paiva, D., M., B., 2012, Recursos de Acessibilidade para Auxiliar a Navegação de Estudantes Cegos em um Editor de Diagramas Anais do $23^{\circ}$ Simpósio Brasileiro de Informática na Educação (SBIE 2012), ISSN 2316-6533, Rio de Janeiro, 26-30 de novembro de 2012.

[15] Cappelli, C, 2009. Uma Abordagem para Transparência em Processos Organizacionais Utilizando Aspectos, 2009. f 329. Tese de Doutorado. Pontifícia Universidade Católica do Rio de Janeiro, Departamento de Informática, 2009, Rio de Janeiro, 2009.

[16] Marew, T., Bae, D., H., 2006. Using Classpects for Integrating non-functional and functional requirements. Proceedings of the 24th IASTED International Multi-Conference Software Engineering, Innsbruck, Austria, fevereiro/2006.

[17] NVDA, 2016, NonVisual Desktop Access. Disponível em: http://nvd3.org, verificado em setembro/2016.

[18] DOSVOX, 2016. Projeto DOSVOX. Disponível em: http://intervox.nce.ufrj.br/dosvox/download.htm, verificado em agosto/2016. 